\title{
Enhancement of Grid Stability with A Possible Configuration of Motor-Generator Pair for Renewable Energy Integration
}

\author{
A. Sowmiya, A. Preethi and Dr.N. Mohana priyaa
}

\begin{abstract}
The Synchronous generator, Converters does not have inherent inertia which is important for frequency response. More complex interaction induced by renewable energies causes problems of power system dynamics, for example damping oscillation. In addition, converters alone cannot support high fault current, leading to limitation of some existing control schemes during transient events. The stable operating condition and strategies of feedback control is ensured by using Synchronous Motor-generator pair is deal with capacity optimization for renewable energy to achieve grid connection. The rotor angle relation, active power regulation, small signal stability and frequency response are important for inertia and stability of grid. However, compared with converters, synchronous generator has some advantages to solve fore mentioned problems. Therefore, this study proposes a synchronous motor-generator pair (MGP) system with a stochastic fuzzy controller as a possible gridconnection way for high penetration of renewable energies with Fuzzy controller to improve stability. Finally, the simulation result has been derived in MATLAB /Simulink with the required formulation.
\end{abstract}

Keywords- Renewable Energy Integration, Inertia, Synchronous Motor-Generator Pair, Stochastic Fuzzy Controller.

\section{INTRODUCTION}

$\mathrm{T}$ HE wind and solar photovoltaic (PV) had record additions for the second consecutive year, accounting for about of new installations. The Penetration rate of more than even higher has appeared in some countries and districts. However, high penetration rate of renewable energies also brings challenging reliability and security issues to power grid. One major challenge is frequency instability induced by replacement of synchronous generator. The Rotor speed of synchronous generator is tightly coupled with grid frequency hence its moment of inertia can be extracted to support

A. Sowmiya, PG Scholar, Department of EEE, Vivekanandha College of Engineering for Women, Elayampalayam, Namakkal, Tamilnadu. E-mail:Sowmiyadurai92@Gmail.Com

A. Preethi, Assistant Professor, Department of EEE, Vivekanandha College of Engineering for Women, Elayampalayam, Namakkal, Tamilnadu. E-mail:agpspreethi@gmail.com

Dr.N. Mohana Priyaa, Professor/Head, Department of EEE, Vivekanandha College of Engineering for Women, Elayampalayam, Namakkal,Tamilnadu.E-mail:monapriyaa123@gmail.com

DOI : 10.9756/BIJPSIC.2215 frequency deviation. However, renewable energy sources generally cannot provide enough inertia. For example, doubly fed induction generator (DFIG) only has limited inertia response, the rotor speed of permanent magnet synchronous generator is completely decoupled with grid frequency and its inertia response does not even exist, as well as solar PV.

\section{A. Fault Condition}

In most cases, they operate with maximum power point tracking mode hence the active power interaction with grid depends on fluctuation, leading to lack of enough inertia energy when necessary. A second major challenge is complexity of power system dynamics. With more and more renewable energy sources being connected to the grid, the complexity is also increasing because of non-linearity and many other factors including fluctuation, different wind turbines, control strategies and parameters, penetration rate and operating region. This will cause uncertainty of dynamic interaction between renewable energy and power flow. One of the most concerns is damping control. In recent years, some power oscillation events have been observed in wind farms consisting. Hence it is necessary to improve damping capability for power grid with high penetration of renewable energy Lots of inertia and damping control methods achieved by converter have been proposed to solve abovementioned problem. A control method called virtual inertia or virtual synchronous generator is proposed to make renewable energies have similar ways like synchronous generator to enhance stability. For wind power, kinetic energy of rotor can be released to support grid frequency and damp oscillation. For PV, an auxiliary energy storage system is used to achieve enough power interaction with grid.

Some auxiliary damping controllers are also designed for wind turbines to enhance damping. However, it is always not ability to support high short circuit current when large disturbance events happen, hence its overload and transient voltage supporting abilities are not as good as synchronous generator. Fluctuation and some specific operation modes, as well as cost concerns also make it difficult for renewable energy sources to provide enough power for dynamic process.

It can be seen obviously from above discussion that synchronous generator being gradually replaced by renewable energy sources makes future grid a configuration dominated by converters, which may lose some good characteristics of traditional power source.

A highly-reliable power network with large scale penetration of distributed renewable resources. Moreover, 
some research has also tried to reuse retired generator as synchronous condenser to improve grid stability not only for frequency response but short-circuit performance.

Therefore, based on the fact that synchronous machine and Synchronization are significant for grid stability, this paper proposes a possible solution, synchronous motor-generator pair (MGP) system, to solve stability issues. Power generated by renewable energy is used to drive synchronous motor, which operates as a primary mover of synchronous generator. The generator is then connected to grid. For the purpose of grid stability, it is necessary to study this special dual synchronous machine system from power system point of view. Therefore, this paper investigates its characteristics related to small signal performance.

\section{RENEWABLE ENERGY INTEGRATION}

Renewable Energy Integration focuses on incorporating renewable energy, distributed generation, energy storage, thermally activated technologies, and demand response into the electric distribution and transmission system. A systems approach is being used to conduct integration development and demonstrations to address technical, economic, regulatory, and institutional barriers for using renewable and distributed systems. In addition to fully addressing operational issues, the integration also establishes viable business models for incorporating these technologies into capacity planning, grid operations, and demand-side management.

\section{A. Objectives of Renewable Energy Integration}

The goal of Renewable energy integration is to advance system design, planning, and operation of the electric grid :

- To reduce carbon emissions and emissions of other air pollutants through increased use of renewable energy and other clean distributed generation.

- To increase asset use through integration of distributed systems and customer loads to reduce peak load and thus lower the costs of electricity.

- To support achievement of renewable portfolio standards for renewable energy and energy efficiency.

- To enhance reliability, security and resiliency from micro-grid applications in critical infrastructure protection and highly constrained areas of the electric grid.

- To support reductions in oil use by enabling plug-in electric vehicle (PHEV) operations with the grid.

\section{RENEWABLE ENERGY}

Renewable energy is energy that is collected from renewable resources, which are naturally replenished on a human timescale, such as sunlight, wind, rain, tides, waves, and geothermal heat.

\section{A. Typesisedis}

There are five types of renewable energy:

- Solar.

- Wind.

- Geothermal.

- Municipal Solid Waste.
- Biomass.

\section{FUEL CELL ENERGY}

A fuel cell produces electricity through a chemical reaction, but without combustion. It converts hydrogen and oxygen into water and in the process also creates electricity. It's an electro-chemical energy conversion device that produces electricity, water, and heat. Fuel cells operate much like a battery, except they don't require electrical recharging. A battery stores all of its chemicals inside and coverts the chemicals into electricity. Once those chemicals run out, the battery dies. A fuel cell, on the other hand, receives the chemicals it uses from the outside; therefore, it won't run out. Fuel cells can generate power almost indefinitely, as long as they have fuel to use. The reactions that produce electricity happen at the electrodes. Every fuel cell has two electrodes, one positive, called the anode, and one negative, called the cathode. These are separated by an electrolyte barrier.

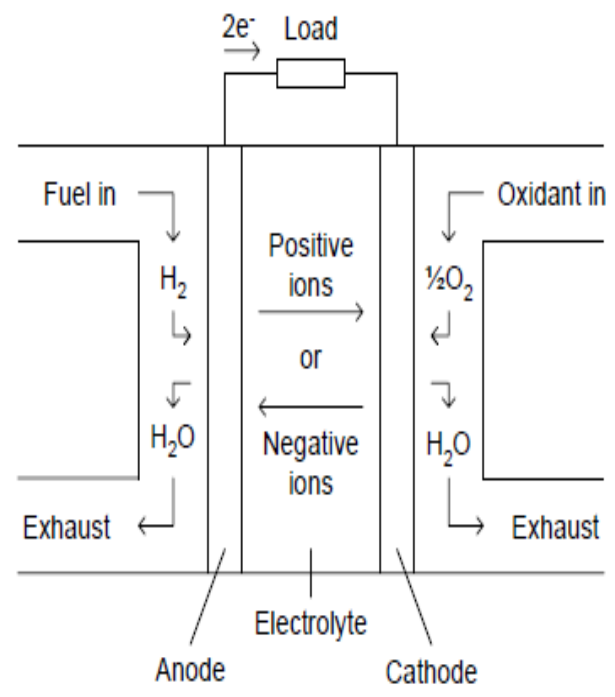

Figure 1: L Basic Fuel Cell Diagram

Fuel goes to the anode side, while oxygen (or just air) goes to the cathode side. When both of these chemicals hit the electrolyte barrier, they react, split off their electrons, and create an electric current. A chemical catalyst speeds up the reactions here. Two chemical reactions occur in the fuel cell at the respective electrodes:

- At the anode, the catalyst oxidizes the fuel and splits it into positive and negative ions. The positive ions pass through the electrolyte while the electrons pass through the external circuit.

- At the cathode, the ions combine with the electrons and react with oxygen to create water or carbon dioxide.

Electrochemical reaction occurring at the electrodes is as follows:

As the result of the reactions, fuel is consumed, either water or carbon dioxide is created as the by-product and electric current is created. The positively charged hydrogen cells move between the two electrodes to create a flow of electricity which is directed outside the cell to provide electricity. The electric power created is known as the load. 
Fuel cells are electrochemical devices. A fuel cell system generally consist of three main parts namely a fuel processor (reformer) which converts fuels such as natural gas to hydrogen, the fuel cell itself, where the electrochemical processes take place and the power is generated and the power conditioner, which converts the DC voltage to AC and enables grid-connection. The positively charged hydrogen cells move between the two electrodes to create a flow of electricity which is directed outside the cell to provide electricity. The electric power created is known as the load. A fuel cell is a device that uses hydrogen (or hydrogen-rich fuel) and oxygen to create electricity by an electrochemical process. A single fuel cell consists of an electrolyte sandwiched between two thin electrodes (a porous anode and cathode) Hydrogen, or a hydrogen-rich fuel, is fed to the anode where a catalyst separates hydrogen's negatively charged electrons from positively charged ions (protons) At the cathode, oxygen combines with electrons and, in some cases, with species such as protons or water, resulting in water or hydroxide ions, respectively.

The electrons from the anode side of the cell cannot pass through the membrane to the positively charged cathode; they must travel around it via an electrical circuit to reach the other side of the cell. This movement of electrons is an electrical current. The amount of power produced by a fuel cell depends upon several factors, such as fuel cell type, cell size, the temperature at which it operates, and the pressure at which the gases are supplied to the cell Still, a single fuel cell produces enough electricity for only the smallest applications.

Therefore, individual fuel cells are typically combined in series into a fuel cell stack. A typical fuel cell stack may consist of hundreds of fuel cells. Fuel cells are classified primarily by the kind of electrolyte they employ. This determines the kind of chemical reactions that take place in the cell, the kind of catalysts required, the temperature range in which the cell operates, the fuel required, and other factors.

\section{Synchronous Motor-GENERATOR PAir SySTEM}

Motor-Generator Pair consists of two synchronous machines, one operates as a motor and the other as a generator. Shafts of two machines are coupled so they can rotate at the same speed. Power generated by renewable energies are converged to drive the motor. The motor replaces steam turbine or hydro-turbine a primary mover of the generator, which is a main difference from traditional power generation unit.

Moment of inertia is inherently provided by two electric machines and stability control can be achieved by two excitation systems. In addition, short circuit capacity of the whole system is enhanced by this way. It can be seen that the MGP system is actually a new approach for renewable energy sources to achieve grid-connection. Converters of different kinds of renewable energies remain the same, which means that there is no need to add a high power converter to drive the MGP. With the proposed MGP system, depicts a possible configuration of future power grid with high penetration of renewable energies. One part of renewable energies is still connected to the grid in traditional way and another part can use MGP to provide inertia, damping and other related stability control.

Optimization works of proportion between these two parts are necessary to achieve better performance. In Fig.b, some traditional power plants will still exist when the penetration rate is high. Using MGP system makes the future grid a configuration dominated by synchronous machines, which is similar with existing multi-machine power system. Some theories and experiences can be used for operation. In terms of efficiency and cost, efficiency of a large hydrogen-cooled generator (200 MW or higher) is more than $98 \%$ at normal rating , hence MGP with two synchronous machines can reach $96 \%$ or even higher.

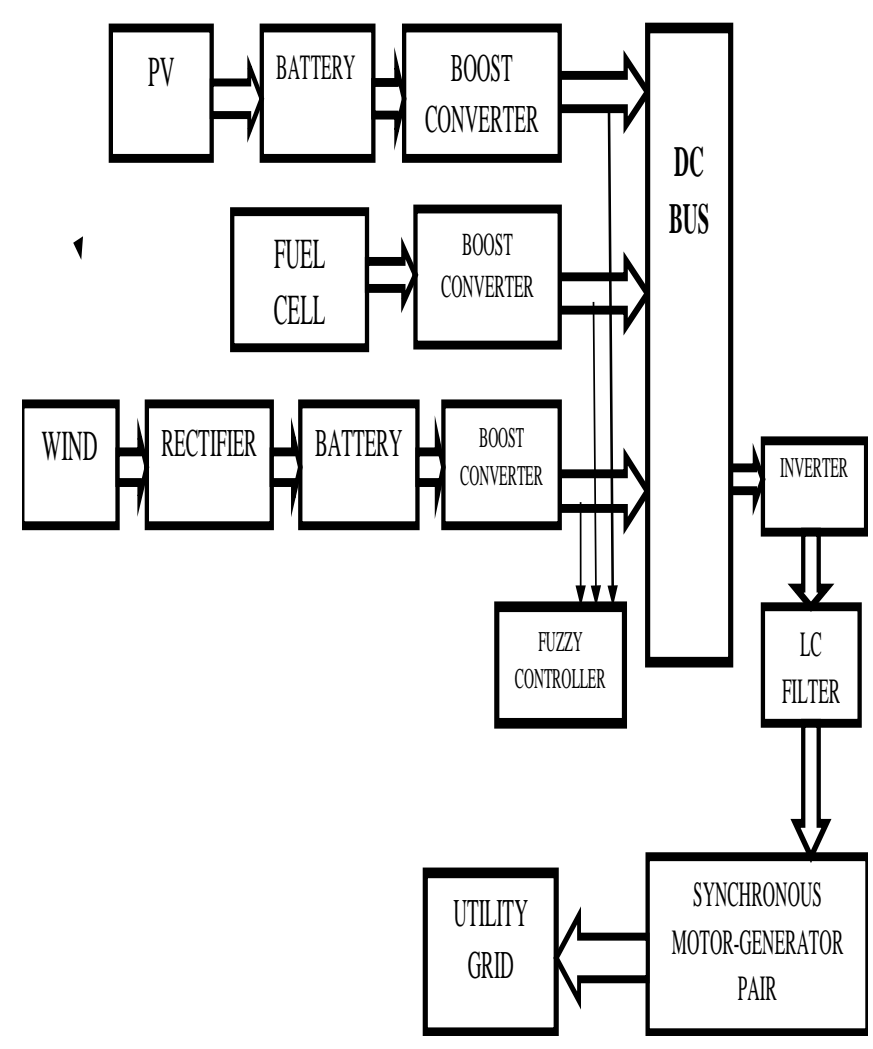

Figure 2: Proposed Block Diagram

\section{Simulation Results}

MATLAB (matrix laboratory) is a numerical computing environment and fourth-generation programming language. Developed by Math works, MATLAB allows matrix manipulation, creation of user interfaces and interfacing with programs written in other languages including $\mathrm{C}, \mathrm{C}++$, Java and FORTRAN.

Although MATLAB is intended primarily for numerical computing, an optional toolbox uses the MuPAD symbolic engine, allowing access to symbolic computing capabilities. An additional package, Simulink adds graphical multi-domain simulation and model-based design for dynamic and embedded system. 
A. Simulink Circuit Model

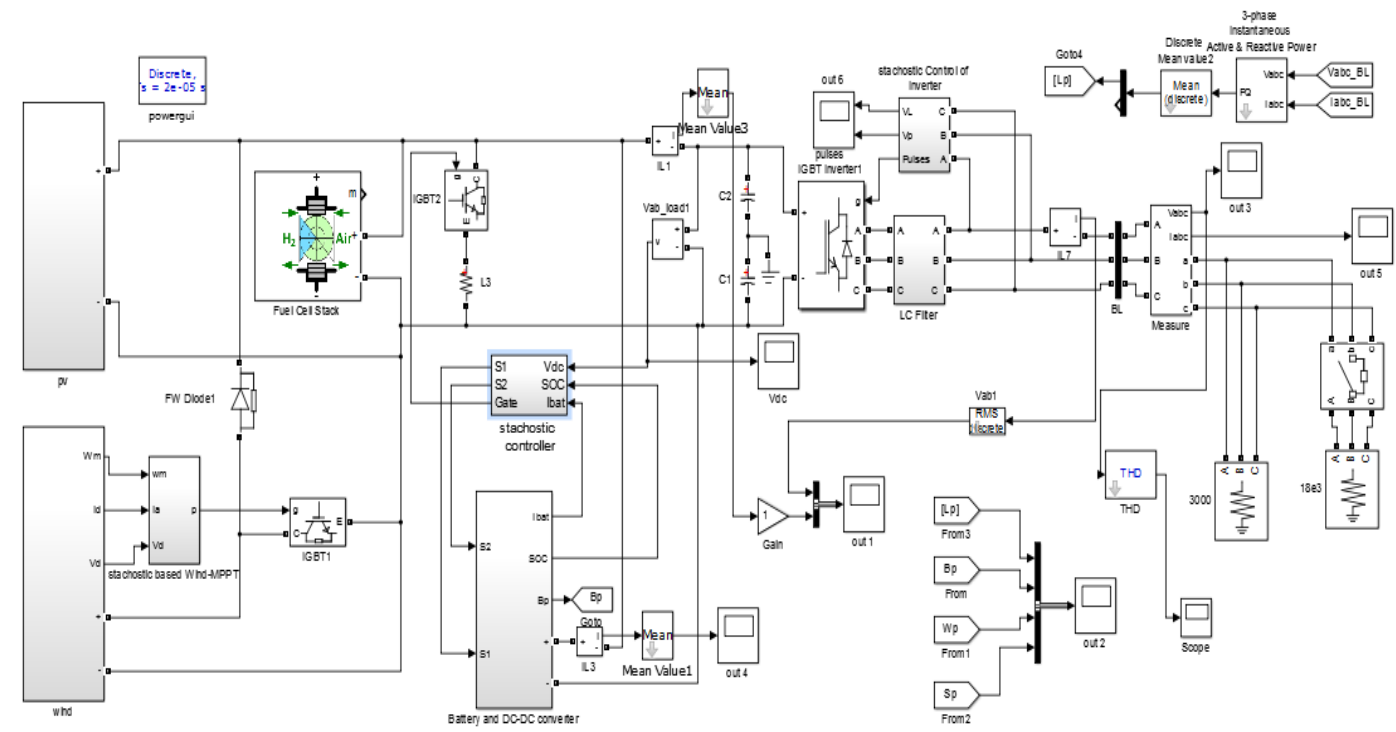

Figure 3: Overall Simulation Model

VII. SiMULATION RESULTS

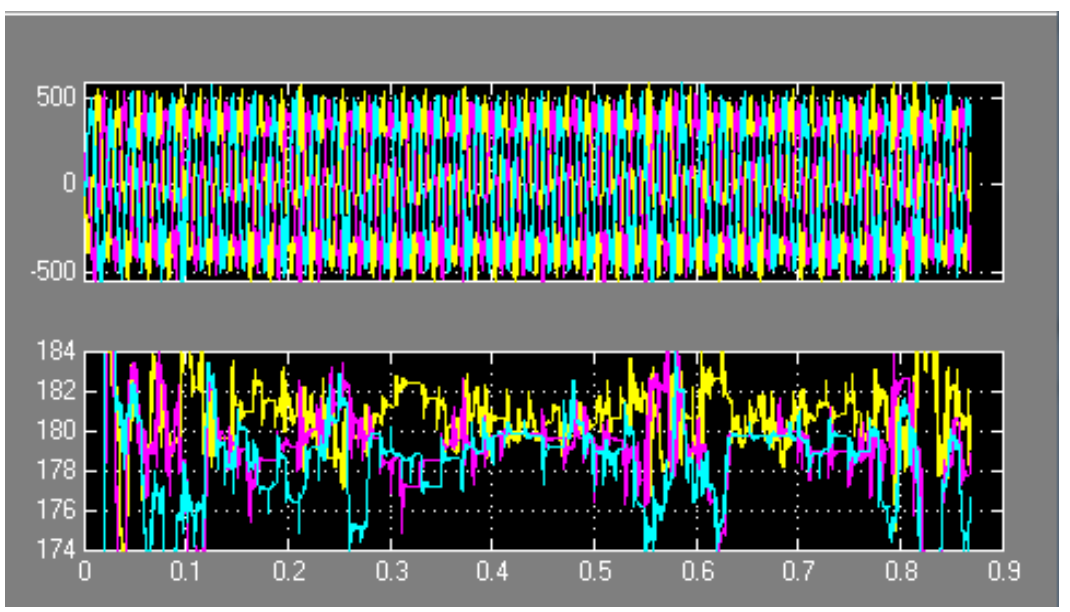

Figure 4: With Motor-Generator Pair Output Waveform

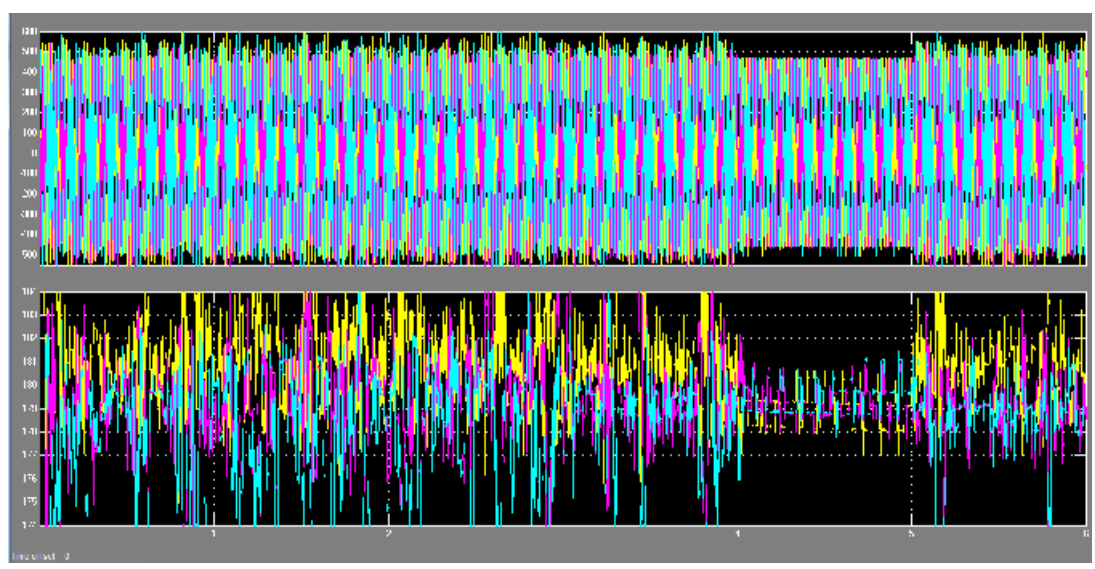

Figure 5: Without Motor-Generator Pair 


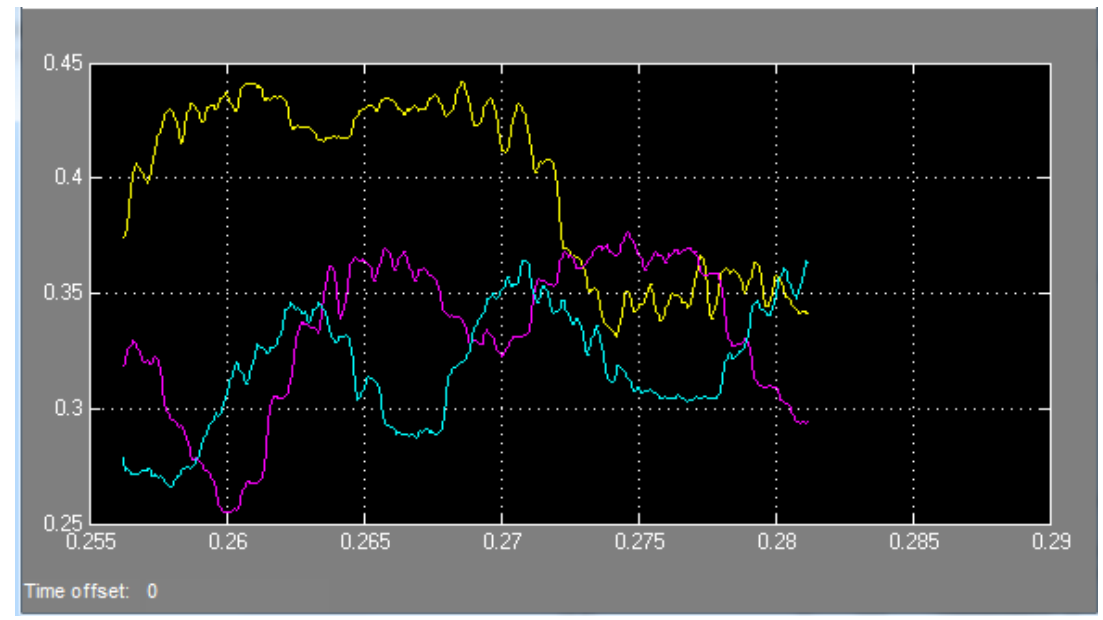

Figure 6: Output Waveform of THD

\section{CONCLUSION}

In this project, the MGP system based synchronous machines to provide a possible future power grid solution with high penetration of renewable energy and to enhance its stability. The damping level, and efficiency of the MotorGenerator pair (MGP) are discussed. The stochastic Fuzzy controller is used for analysing rotor angle relation, active power regulation, small signal stability and frequency response are verified through simulation results and reduced the THD value to the grid.

\section{FUTURE WORK}

On maintaining the damping level and improvement of efficiency in the Future Grid by Motor-Generator pair (MGP) with the change of ANFIS (Adaptive Neuro Fuzzy Interface System) Algorithm instead of Stochastic Fuzzy controller and the THD value will be minimized through the simulation results. Adaptive Neuro Fuzzy Interface System is a more efficient and optimal way for best parameters. Adaptive Neuro Fuzzy Interface System is done by interfacing the Neural network and Fuzzy controller which is used for analysing frequency response, active power regulation and efficiency.

\section{REFERENCES}

[1] REN. PS.: 'Renewables 2016: Global Status Report' (REN21 Secretariat, Pp. 6-7, 2016.

[2] K.G. Boroojeni, M.H. Amini and S.S. Iyengar, "Overview of the security and privacy issues in smart grids", Smart grids: security and privacy issues’ (Springer International Publishing), Pp. 1-16, 2017.

[3] A. Essl and A. Ortner, "Machine learning analysis for a flexibility energy approach towards renewable energy integration with dynamic forecasting of electricity balancing power", IEEE transactions power systems, 2017.

[4] J. Xia, A. Dyśko and J. O'Reilly, "Future stability challenges for the UK network with high wind penetration levels", IET Gener. Transm. Distrib., Vol. 9, No. 11, Pp. 1160-1167, 2015.

[5] J. Conto, "Grid challenges on high penetration levels of wind power", IEEE Power and Energy Society General Meeting, San Diego, USA, Pp. 1-3, 2012.

[6] Y. Wang, V. Silva and M. Lopez-Botet-Zulueta, "Impact of high penetration of variable renewable generation on frequency dynamics in the continental Europe interconnected system”, IET Renew. Power Gener., Vol. 10, No. 1, Pp. 10-16, 2016.
[7] D.Y. Eom, S.L. Hong, C.H. Kim, S.J. Roh, J.D. Kong and K.R, "Park The power characteristic results according to the superconducting magnet coil load test of the motor generator system”, IEEE Trans. Power Syst., 2015.

[8] H. Golpîra, H. Seifi and A.R Messina, "Maximum penetration level of micro-grids in large-scale power systems: frequency stability viewpoint”, IEEE Trans. Power Syst., Vol. 31, No. 6, Pp. 5163-5171, 2016.

[9] X. Liang, "Emerging power quality challenges due to integration of renewable energy sources”, IEEE Transaction on industrial application, 2016.

[10] V. Gevorgian, Y. Zhang and E. Ela, "Investigating the impacts of wind generation participation in interconnection frequency response", IEEE Trans. Sustain. Energy, Vol. 6, No. 3, Pp. 1004-1012, 2015.

[11] N. Javaid, I. Ullah, M. Akbar, Z. Iqbal, F. Ali Khan, N. Alrajeh and M. Souheil Alabed, "An intelligent load management system with renewable energy integration for smart homes" IEEE Transactions 2016.

[12] S. Muller, M. Deicke and R.W. De Doncker, "Doubly fed induction generator systems for wind turbines”, IEEE Ind. Appl. Mag., Vol. 8, No. 3, Pp. 26-33, 2002.

[13] Y.V. Pavan Kumar and R. Bhimasingu, "Improving power quality in micro grids using virtual motor-generator set based control scheme", IEEE Transactions 2016.

[14] I.D. Margaris, S.A. Papathanassiou and N.D. Hatziargyriou, "Frequency control in autonomous power systems with high wind power penetration”, IEEE Trans. Sustain. Energy, Vol. 3, No. 2, Pp. 189-199, 2012.

[15] M.M. Hossain and M.H. Ali, "Future research directions for the wind turbine generator system”, Renew. Sustain. Energy Rev., Vol. 49, Pp. 481-489, 2015.

[16] P.M. Vahdati, A. Kazemi and M.H. Amini, "Hopf bifurcation control of power systems nonlinear dynamics via a dynamic state feedback controller-- part i: theory and modelling”, IEEE Trans. Power Syst., pp. 1- 1, 2016.

[17] L. Angel and J. Viola, "Design and statistical robustness analysis of fopid, iopid and simc pid controllers applied to a motor-generator system”, IEEE Latin America Transactions, 2015.

[18] M. Moradzadeh, H. Shayeghi and L. Vandevelde, "Impact of increased penetration of large-scale wind farms on power system dynamic stability-A review", Proc. Int. Conf. Environment and Electrical Engineering (EEEIC), Rome, Italy, Pp. 1522-1526, 2015.

[19] S. Hong, W. Choi, S. Ahn, G. Lee, H. Son, Y. Kim and H. Kim, "Motor-Generator control to improve shift quality for a dual mode power split transmission”, EVS27 International Battery, Hybrid and Fuel Cell Electric Vehicle Symposium, 2013.

[20] J. Ma, S. Wang and Z. Wang, "Power system energy stability region based on dynamic damping theory”, IET Gener. Transm. Distrib., Vol. 10, No. 12, Pp. 2907-2914, 2016.

[21] L.C. Gross, "Sub-synchronous grid conditions: New event, new problem, and new solutions”, Proc. Int. Conf. Western Protect Relay, Spokane, WA, Pp. 1-5, 2010. 
[22] Y.H. Wan, "Synchronized phasor data for analyzing wind power plant dynamic behavior and model validation", Technical Report, NREL, 2013.

[23] M. Wu, R. Sun and L. Cheng, "Parameter sensitivity analysis for sub synchronous control interactions in wind-integrated power systems", Proc. Int. Conf. CIGRE Grid of the Future Sym., Houston, TX, USA, 2014.

[24] N. Saxena, B. Singh, A.L. Vyas, I. Hussain, "Integration of renewable energy with storage system to single phase distribution system”, IEEE Transaction, 2017.

[25] Q.C. Zhong and G. Weiss, "Synchronverters: inverters that mimic synchronous generators”, IEEE Trans. Ind. Electron., Vol. 58, No. 4, Pp. 1259-1267, 2011.

[26] J. Ma, Y. Qiu, Y. Li, "Research on the impact of DFIG virtual inertia control on power system small-signal stability considering the phaselocked loop”, IEEE Trans. Power Syst., pp. 1-1, 2016.

[27] A.E. Leon, G. Revel and D.M. Alonso, "Wind power converters improving the power system stability”, IET Gener. Transm. Distrib., Vol. 10, No. 7, Pp. 1622-1633, 2016.

[28] N. Mithulananthan, R. Shah and K.Y. Lee, "Small-disturbance angle stability control with high penetration of renewable generations", IEEE Trans. Power Syst., Vol. 29, No. 3, Pp. 1463-1472, 2014.

[29] S. Wei, Y. Zhou, S. Li and Y. Huang, "A Possible configuration with motor-generator pair for renewable energy integration”, CSEE Journal of Power and Energy systems, 2017. 